
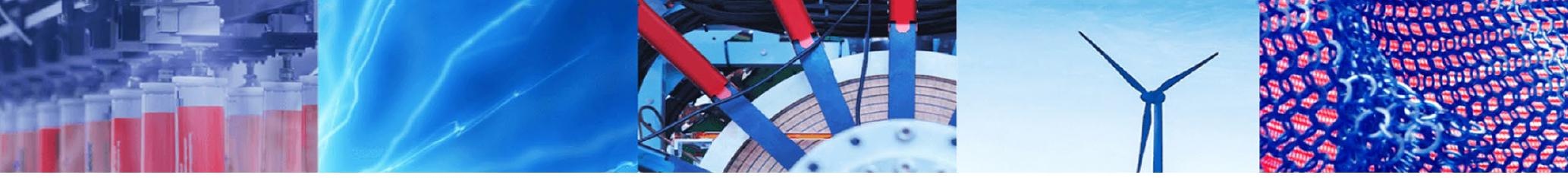

Research Article

\title{
Effect of piston bowl geometry modification and compression ratio on the performance and emission characteristics of DI diesel engine
}

\author{
S. K. Gugulothu' ${ }^{1}$
}

Received: 7 April 2020 / Accepted: 10 June 2020 / Published online: 18 July 2020

(c) Springer Nature Switzerland AG 2020

\begin{abstract}
The present study describes the experimental investigations carried out to study ne influ. ce of modified piston bowl geometry at a constant speed of the combustion, performance and emission ch $/ \mathrm{ra}$ ristics of a direct injection compression ignition diesel engine. The modified piston profiles, namely hemispherical comb ion chamber (HCC) and toroidal combustion chamber (TCC), are manufactured with a baseline compressirn ra o of 17.1, and the effects of compression ratio $(16: 1,17: 1$ and 18:1) are analyzed. Experiments are carried out with $\ldots$ uncel for low load to full load conditions for better understanding. With an increasing compression ratio of the engli. TCC piston geometry has shown better improvement in brake thermal efficiency, carbon monoxide and h__ ronon emissions than HCC. However, a slight penalty in $\mathrm{NO}_{x}$ emission is observed with increasing compression ratio and TCC piston geometry. In-cylinder peak pressure, net heat release rate and rate of pressure rise are increased signifiantly with increasing compression ratio and the use of TCC geometry.
\end{abstract}

Keywords Toroidal combustion chamber · Hemisph_rical c bystion chamber - Exhaust gas recirculation . Compression ratio $\cdot$ Performance and emission $c^{\prime}$ racteristics

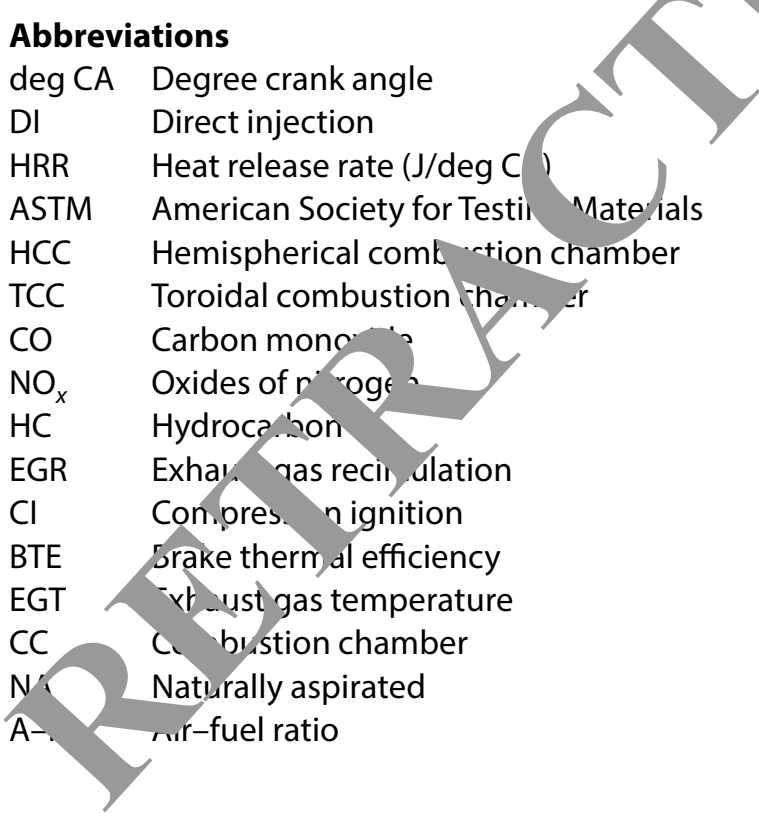

\section{Introduction}

The annual energy outlook revealed that the total energy consumption for transportation sector was $38 \%$ and global liquid fuel consumption was $68 \%$ in the year 2018 and if it continues in the same way, then the usage of the liquid fuel for transportation sector may rise up to $72 \%$ in 2035 [1]. In Indian transportation sector, compression ignition $(\mathrm{Cl})$ engines are contributing a major share because of which the original engine manufacturers (OEMs) are striving to achieve high performance and low emissions to meet Bharat stage $\mathrm{VI}$ emission norms that are to be implemented w.e.f. April 1, 2020. Homogeneous charge compression ignition $(\mathrm{HCCl})$ technology is a promising one that targets both performance and emissions of $\mathrm{Cl}$ engines. The $\mathrm{HCCl}$ combustion process has the potential to reduce $\mathrm{NO}_{x}$ and particulate emissions, while achieving high thermal

S. K. Gugulothu, santoshgk1988@gmail.com | 'Department of Mechanical Engineering, National Institute of Technology,

Tadepalligudem, Andhra Pradesh, India. 
efficiency [2-4]. However, it has a major drawback, higher $\mathrm{HC}$ and $\mathrm{CO}$ emissions and uncontrolled combustion when fueled with high cetane rating fuel like diesel [5]. Little modification on naturally aspirated $\mathrm{Cl}$ engine may make it possible to commercialize $\mathrm{HCCl}$ technology. In this context, design of combustion chamber (CC) plays a vital role in achieving better performance and emissions characteristics of direct injection $\mathrm{Cl}$ engines. At the other hand, performance, combustion and emission characteristics of $\mathrm{Cl}$ engines can be better only when high degree of air swirl and turbulence takes place in the combustion chamber during suction and compression strokes. The swirl-squish interaction in the combustion chamber produces the turbulent flow field when the piston moves toward TDC which could be obtained by changing the default piston geometry of hemispherical combustion chamber (HCC) [6-8]. In order to meet the mandated emission norms, it is important to provide alteration in the piston bowl geometry for better air-fuel mixing throughout the combustion chamber thereby reducing emissions as well as elevated engine performance $[9,10]$. With the use of smaller piston bowl size, it is possible to obtain the better swirl and high heat release rate (HRR) [11]. However, by increasing piston bowl radius, engine characteristics may affect adversely. Brijesh et al. investigated numerically and achieved t high turbulence intensity in various combustion chamber. such as double lip, Mexican hat, bow and toroida: [12]. It was found that toroidal combustion chamber crea $d$ setter turbulence out of all the combustion ch ambers ?]. Jaichandar et al. [13] investigated the effe $t \mathrm{t} c$ oroidal reentrant combustion chamber (TRCC) $\geqslant d$ hem, yerical combustion chamber (HCC) on brake thermal efficiency (BTE) and emission characteristics of a single cylinder direct injection $\mathrm{Cl}$ engine. It was found that the BTE was $33.07 \%$ with TRCC and $31.48 \%$ with HCC. Huge reduction of $20.7 \%$ in hydrocarbon $(\mathrm{HC})$ emissions was also noted with TRCC. $\mathrm{NO}_{x}$ was increased by $9 \%$ in TRCC, i.e., $784 \mathrm{ppm}$ and $712 \mathrm{ppm}$ for TRCC and HCC, respective fy. Jyothi et al. had investigated the effect of TCC geor. $r y$ an a single cylinder $\mathrm{Cl}$ engine [14]. It was found that $\mathrm{BT} \mathrm{L}_{\mathrm{L}}$ reased by $2.94 \%$, and BSFC decreased by $1.3^{\circ}$ as compa ed to HCC geometry. $\mathrm{HC}$ and $\mathrm{CO}$ emissions we $3.5 \%$, respectively. However, $\mathrm{NO}_{x}$ emiss $\mathrm{ns}$ increased by $3.5 \%$ by using TCC geometr [14]. Th detailed literature as shown in Table 1 ass rtai th- TCC geometry had shown better engine ha. teristics over HCC geometry except increased $N$ emissic is.

Many researchers эve obtained improved results on engine $p$ mance, nainly brake thermal efficiency and emiss ch conteristics such as $\mathrm{HC}$ and $\mathrm{CO}$ from $\mathrm{Cl}$ engines whe. $C \mathrm{C}$ has been used [13, 14, 28]. However, the $m_{i}$ rinal inc, ement was found in $\mathrm{NO}_{x}$ emissions due to high te $m_{1}$, rature rise during combustion. To control the increased $\mathrm{NO}_{x}$ emissions in $\mathrm{Cl}$ engine, two best poscible ways can be adopted, either the use of exhaust gas irculation (EGR) $[29,30]$ or reduction in compression ra io [31]. By using the above two solutions to control $\mathrm{NO}_{x}$ emissions, the uncontrolled combustion limitation of $\mathrm{HCCl}$ can also be resolved. The main motive of the current investigation was to enhance performance and reduce emissions of a conventional $\mathrm{Cl}$ engine by incorporating two methodologies, i.e., compression ratio increment

Table 1 Comparison of piston bowl geome offect on single cylinder

\begin{tabular}{|c|c|c|c|c|c|c|c|c|c|}
\hline \multirow[t]{2}{*}{ Piston bowl } & \multirow[t]{2}{*}{ En necifications } & \multicolumn{7}{|c|}{ Results compared with HCC } & \multirow[t]{2}{*}{ Ref. } \\
\hline & & BTE & BSFC & $\mathrm{CO}$ & $\mathrm{HC}$ & $\mathrm{NO}_{x}$ & $P$ & $\mathrm{HRR}$ & \\
\hline TCC and TPCC & rpm, CR 18:1, IP 210 bar & $\uparrow$ & $\downarrow$ & $\downarrow$ & $\downarrow$ & $\uparrow$ & $\uparrow$ & $\uparrow$ & [15] \\
\hline TCC and TRCC & 1500 rpm, CR 17.5:1, IP 210 bar & $\uparrow$ & $\downarrow$ & & & $\uparrow$ & & & [16] \\
\hline TPCC and TCC & 1500 rpm, CR 17.5:1 & $\uparrow$ & $\downarrow$ & $\downarrow$ & $\downarrow$ & $\uparrow$ & $\uparrow$ & $\uparrow$ & [17] \\
\hline $\mathrm{CC}$ & CR 17.5:1, RP 3.5 kW, IP 220 bar & $\uparrow$ & & $\downarrow$ & & $\uparrow$ & & $\uparrow$ & [18] \\
\hline TCC & RP 5.2 kW, IP 220 bar, CR 19.5:1 & $\uparrow$ & & $\downarrow$ & $\downarrow$ & $\uparrow$ & $\uparrow$ & $\uparrow$ & [19] \\
\hline & 1500 rpm CR 18:1, RP 5.2 kW, IP 210 bar & $\uparrow$ & $\downarrow$ & $\downarrow$ & $\downarrow$ & $\uparrow$ & $\uparrow$ & $\uparrow$ & [20] \\
\hline & 1700 rpm, CR 18:1, RP 4.5 kW, IP 185 bar, & $\uparrow$ & $\downarrow$ & $\downarrow$ & $\downarrow$ & $\uparrow$ & & & [21] \\
\hline & 1500 rpm, CR 17.5:1, RP 3.5 kW & $\uparrow$ & $\downarrow$ & $\downarrow$ & $\downarrow$ & $\uparrow$ & $\uparrow$ & $\uparrow$ & [22] \\
\hline $\mathrm{HCL}_{\mathrm{L}}, 21, \mathrm{CB} 2$ and TCC & 1500 rpm, CR 17.5:1, RP 3.5 kW & $\uparrow$ & $\downarrow$ & $\downarrow$ & $\downarrow$ & $\uparrow$ & $\uparrow$ & $\uparrow$ & [23] \\
\hline $\mathrm{HCC}$, So and TCC & 1500 rpm, CR 17.5:1, RP 3.5 kW & $\uparrow$ & $\downarrow$ & $\downarrow$ & $\downarrow$ & $\uparrow$ & $\uparrow$ & $\uparrow$ & [24] \\
\hline $\mathrm{CB} 1, \mathrm{CB} 2, \mathrm{CB} 3$ and $\mathrm{CB} 4$ & 1500 rpm, CR 17.5:1, RP 5.2 kW & $\uparrow$ & $\downarrow$ & $\downarrow$ & $\downarrow$ & $\uparrow$ & $\uparrow$ & $\uparrow$ & [25] \\
\hline 6-Wave and standard w-bowl & 1500 rpm, CR 17.5:1, RP 3.5 kW & $\uparrow$ & $\downarrow$ & $\downarrow$ & $\downarrow$ & $\uparrow$ & $\uparrow$ & $\uparrow$ & [26] \\
\hline MSB, DSB and BB & 8000 rpm, CR 17.5:1, RP 5.3 kW & $\uparrow$ & $\downarrow$ & $\downarrow$ & $\downarrow$ & $\uparrow$ & $\uparrow$ & $\uparrow$ & [27] \\
\hline
\end{tabular}

Four-stroke, $\mathrm{DI}, \mathrm{Cl}$ engine characteristics

TPCC trapezoidal combustion chamber, TCC toroidal combustion chamber, HCC hemispherical combustion chamber, HSCC hemisphere combustion chamber, $R P$ rated power, $I P$ injection pressure, $P$ in-cylinder pressure 
and piston modification to TCC geometry. Jaichandar and Annamalai investigated the combined effect of high injection pressure and toroidal combustion chamber (TCC) on $\mathrm{Cl}$ engine and found that engine performance and emissions were improved with TCC and high injection pressure combination. However, an increase in injection pressure was found responsible for $\mathrm{NO}_{x}$ emissions increment due to increased HRR and peak in-cylinder pressure during combustion [32]. Therefore, in the current research one of the key engine design parameters, combustion chamber modification was done. Sagaya Raj et al. [33] studied the air motion for four different geometries for a single cylin$\operatorname{der} \mathrm{Cl}$ engine. They reasoned out that combustion bowl profile played a key role in air-fuel mixing. Performance, combustion and emission characteristics of a diesel engine depend on operating parameters and fuel properties [34] because this diesel engine has to achieve better air movement squish, swirl and turbulence.

This work would also make the existing engine ready to implement $\mathrm{HCCl}$ retrofit in order to attain $\mathrm{BS}-\mathrm{VI}$ emission norms. Experiments were conducted to investigate the combined effect of compression ratio and piston geometry on a single cylinder direct injection $\mathrm{Cl}$ engine with two different combustion chambers HCC (default geometry) and TCC (modified). The engine was run with three corpression ratios (CRs) 16:1, 17:1 and 18:1 and 10\% exhaus gas recirculation (EGR).

\section{Experimental methodology}

Variable compression ratio (VCR), single cylinder, watercooled engine experimental test setup is shown in Fig. 1. Remaining details of the engine setup are shown in Table 2. Engine setup is equipped with rotameter to control water flow rate, which circulates arou ra the engine and around calorimeter at the range of 1 (lit ror) and $250 \mathrm{~L}$ per hour, respectively. The engine s prade to operate on VCR, in which engine $r$ rck was til.ed to suitable scale and desired values of co. ress on ratio that was obtained without stopp ing the en ne.

\begin{tabular}{|c|c|}
\hline Make & Kirloskar TV1 \\
\hline Engine & $3.7 \mathrm{~kW}$ \\
\hline Engine speed & $1500 \mathrm{rpm}$ \\
\hline Cylind hore ands, oke & $87.5 \mathrm{~mm}$ and $110 \mathrm{~mm}$ \\
\hline Compre & $12: 1$ to $18: 1$ \\
\hline Cubic cap acity & $661 \mathrm{cc}$ \\
\hline Piston bowi shape & Hemispherical \\
\hline on bowl diameter & $52 \mathrm{~mm}$ \\
\hline In enter piston bowl depth & $25 \mathrm{~mm}$ \\
\hline aterial and thickness of piston & Cast aluminum, thickness $5 \mathrm{~mm}$ \\
\hline Fuel injector pressure range & 243 bar@full load \\
\hline Fuel injection timing & $23^{\circ} \mathrm{b}$ TDC \\
\hline
\end{tabular}

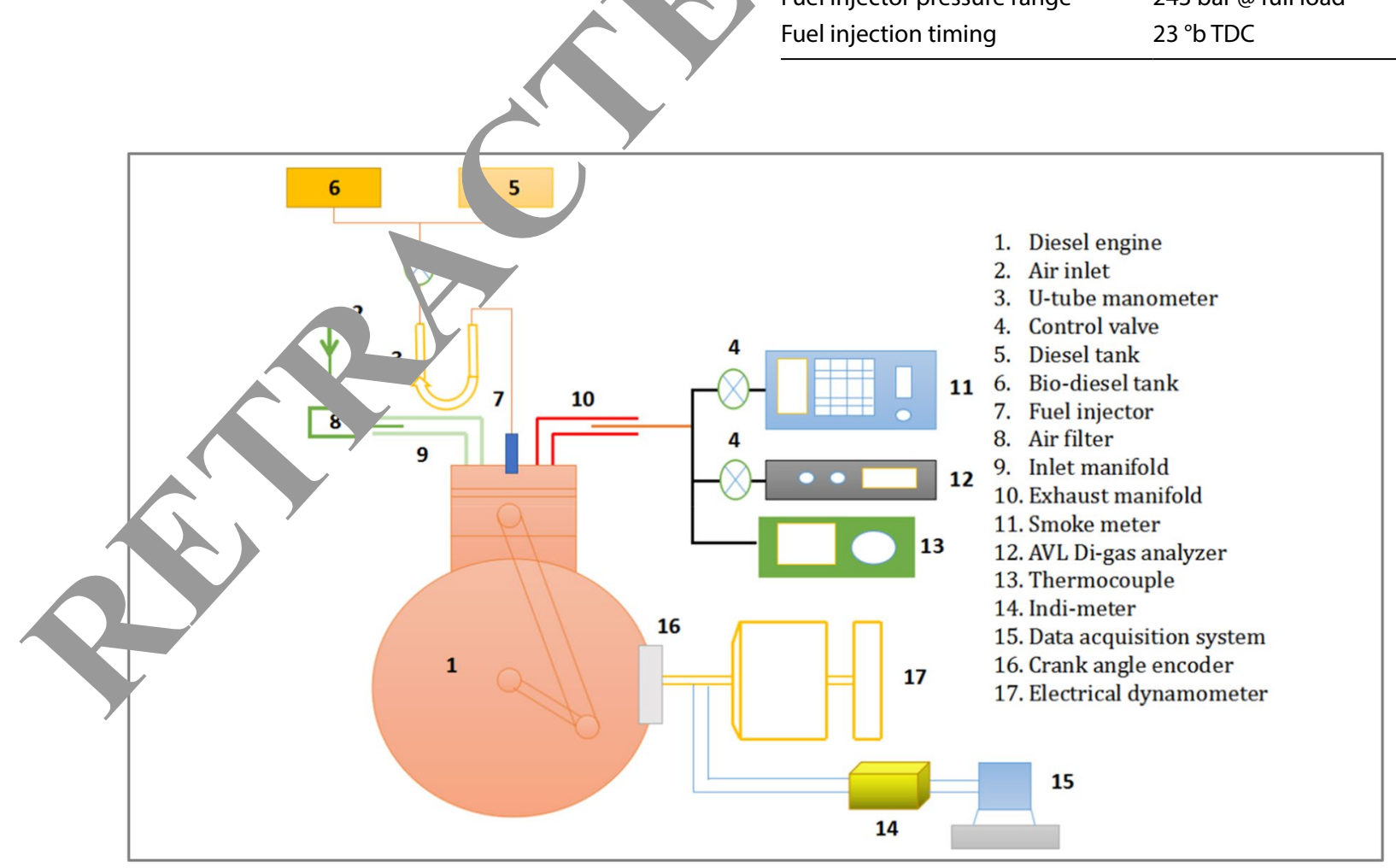

Fig. 1 Schematic diagram of variable compression engine experimental setup using EGR 


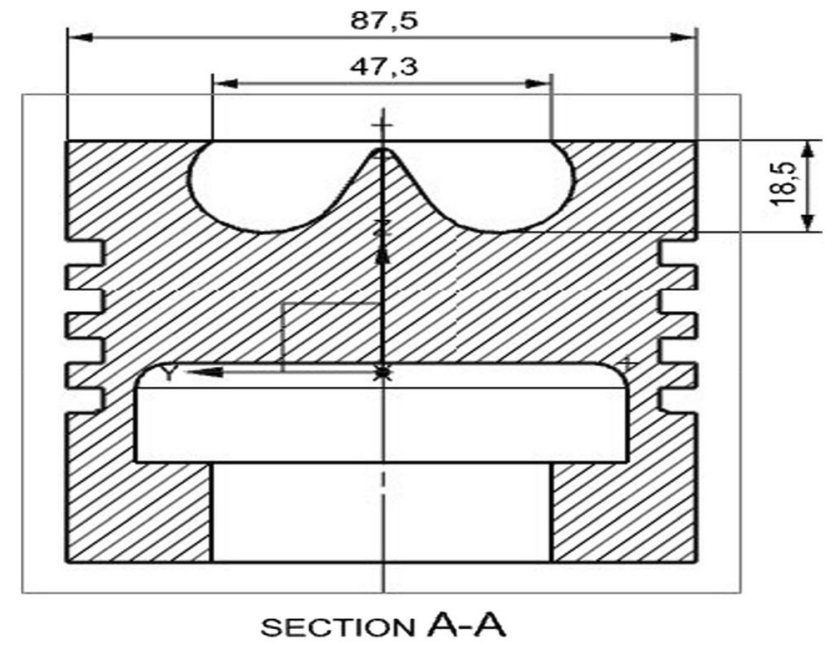

BB-TOROIDAL RE-ENTRANT BASE BOWL

$A \cdot R=0.35, \quad R E \cdot R=0.83, B / B=0.59$

Fig. 2 Toroidal combustion chamber

\subsection{Compression ratio adjustment}

Conventionally available engine with fixed $C R$ was modified to variable compression ratio (VCR) by providing extra variable combustion space. Tilting cylinder block method was used to vary the CR without char ing the piston bowl geometry. With this methor the compression ratio can be changed within ran e from 12:1 to $18: 1 \mathrm{CR}$ without stopping the engine at $\mathrm{t}$. Oad condition. The $C R$ was varied by changing cleara $-e$ volume and by keeping the constant s lep. Jume of the engine. The arrangement of the variable $c$.npression ratio setup is depicted in Fig. One of the important goals of this research was to $r$, ce the $\mathrm{HC}$ and $\mathrm{CO}$ emissions of the engine with ${ }^{\prime} \mathrm{w} \mathrm{NO}_{x}$-rilssions. Therefore, experiment was done on ur.. jmpression ratios ranging from $16: 1$ to $18 \cdot 1$ With 'ne earlier experimental results, it was obser ed $i$ at th engine-out HC emissions were increacea asticarly at below 16:1 CR due to poor combu ion char Keristics; hence, the present study was in esti, ted for the CR beyond 16:1.

\subsection{Mc fic tion in combustion chamber of sta. 'ard engine}

Th. in der air motion, fuel injection timing, injection press and bowl dimensions are some of the important parameters that govern the performance, combustion and emission characteristics of engines [35]. To attain the improved performance and low emissions from the $\mathrm{Cl}$ engine, quality of A-F mixture is the most important controlling parameter. Quality of air-fuel mixing can be achieved either by increasing injection pressure or compression ratio. In this research, to optimize the performance, combustion and emissions characteristic of an engine the hemispherical combustion chamber (HCC) geometry (Fig. 2) was replaced with a toroidal combustion chamber (TCC) (F/g.2). Volumes of both the piton cavities were kept san d fault (HCC) piston cavity volume provided by OEM was cu'sic centimeter and for the modified (TCC) /vas also ke,pt same in order to compare their effect on engi. hehay or. The simulations were carried out with CATIA V5-h. to measure the volume and surface area of $\mid$ ston cavity. The surface area obtained with $\mathrm{HCC}$ and ${ }^{-} \mathrm{CC}$, n cavity was $508.95 \mathrm{~cm}^{2}$ and $517.55 \mathrm{~cm}^{2}$. To en yre, same volume for both the pistons, physical mear rements, using an isopropyl alcohol (liquid) were car, ed It can reach easily crevices of the cavity due to 'ow sur, ce tension property. A flat glass plate with ma halowas kept on the piston head. Isopropyl was pourc "nto the piston cavity through burette from the gi chole. $v$ yume was measured from the amount of liquid rou rom burette.

Variou's test results have shown that TCC geometry produces high amounts of $\mathrm{NO}_{x}$ emissions $[13,14,28]$ with reasing combustion temperature because of rapid and in proved air-fuel mixing. Keeping this factor into consideraion, the existing engine setup was operated with exhaust gas recirculation (EGR) to control the $\mathrm{NO}_{x}$ emissions.

Total twelve experiments were performed on the engine to evaluate various output parameters as shown in Table 3.

\section{Uncertainty analysis}

It is to be observed that in the experimental investigation the possibilities of errors and uncertainties are higher because of the test rig accuracies, regulations and indigenous conditions. In this paper, the square root technique was implemented to the engine trials in order to calculate the uncertainties. The equation is as follows:

$w_{R}=\sqrt{\left(\frac{\partial R}{\partial x_{1}} w_{1}\right)^{2}+\left(\frac{\partial R}{\partial x_{2}} w_{2}\right)^{2}+\cdots+\left(\frac{\partial R}{\partial x_{n}} w_{n}\right)^{2}}$

where $R$ is the dependent factor and function of independent variables.

The engine parameters like brake power, specific fuel consumption, brake specific energy consumption and brake thermal efficiency are mentioned in "Appendix."The overall uncertainty for the experimental study can be calculated as follows: 
Overall uncertainty

$=$ Square root of $\left[\begin{array}{l}(\text { uncertainty of } \mathrm{MFC})^{2}+(\text { uncertainty of } \mathrm{BTE})^{2} \\ +(\text { uncertainty of } \mathrm{BP})^{2}+(\text { uncertainty of } \mathrm{CO})^{2} \\ +(\text { uncertainty of } \mathrm{HC})^{2}+\left(\text { uncertainty of } \mathrm{NO}_{\mathrm{X}}\right)^{2} \\ +\left(\text { uncertainty of } \mathrm{O}_{2}\right)^{2}+\left(\text { uncertainty of } \mathrm{CO}_{2}\right)^{2} \\ +(\text { uncertainty of EGT })^{2}\end{array}\right]$
$=$ Square root of $\left[\begin{array}{l}(1.554)^{2}+(1.764)^{2}+(0.836)^{2}+(1.027)^{2}+(0.839)^{2} \\ +1.479^{2}+(0.838)^{2}+(0.909)^{2}+(1)^{2}\end{array}\right]$

$=3.564 \%$

\section{Results and discussion}

Results obtained from the experiments on the test engine with two different piston geometries HCC and TCC, three different compression ratios 16:1, 17:1 and 18:1 without EGR (Base engine) and 10\% EGR are discussed below. Abbreviations used for the discussion are hemispherical combustion chamber without EGR: base-HCC; toroidal combustion chamber without EGR: base-TCC; hemispherical combustion chamber with 10\% EGR: EGR-HCC; and toroidal combustion chamber with 10\% EGR: EGR-TCC

\subsection{Engine performance improvement}

\subsubsection{Brake thermal efficiency}

Brake thermal efficiency (BTE) vas increastd with increasing $C R$ for both the pisto geometries. However, TCC had shown higher BTE th. HCC due to better combustion and rapid el ation rate of fuel as observed in Fig. 3. At higher compryssion ratio and full engine load, BTE was d _. ased by $3 \%$ with EGR for both the piston geometr. $\mathrm{Tr}$ ement in BTE with EGR was observed dye to $a$ tion of the A-F mixture. The

Table 3 Pro

maximum BTE of $33.12 \%$ was achieved with base-TCC, which was higher, by $5.67 \%$ than base-HCC. This may be due to better air swirling and turbulence in TCC, which led to better combustion of diesel [12]. Similar trends were observed by Vedhraj et al. with different blends of biodiesel in HCC and TCC engine [18].

\subsubsection{Volumetric efficiency}

A significant reduction in the ar ount of in ake air to the cylinder was found with addit. of $E$. $R$ as shown in Fig. 4. These deviations vere obs ed because of the change in the intake $a$ temperature. Volumetric efficiency was increas $4 \mathrm{w}$ a $\mathrm{n}$ icrease in compression ratio from $16^{1}$ to $2: 1$ due to the increase in breathing capaci of the gine. The maximum volumetric efficie, cy obtained $91 \%$ with base-TCC. There was a ginal $\epsilon$, nancement in volumetric efficiency wi TC ronmetry at all specified conditions than HCC.

\subsubsection{Ex iaust gas temperature}

riations of exhaust gas temperature (EGT) with ch ange in compression ratios and piston geometries re depicted in Fig. 5. EGT found decreasing with the increase in $C R$, because of better combustion and reduction in ignition delay as observed in Fig. 8. The use of EGR shows a decrement in EGT due to dilution of A-F mixture. Heat release rate during combustion decreases with EGR addition and causes the EGT reduction. At full engine load, EGT was decreased by almost $9 \%$ at $18: 1$ CR

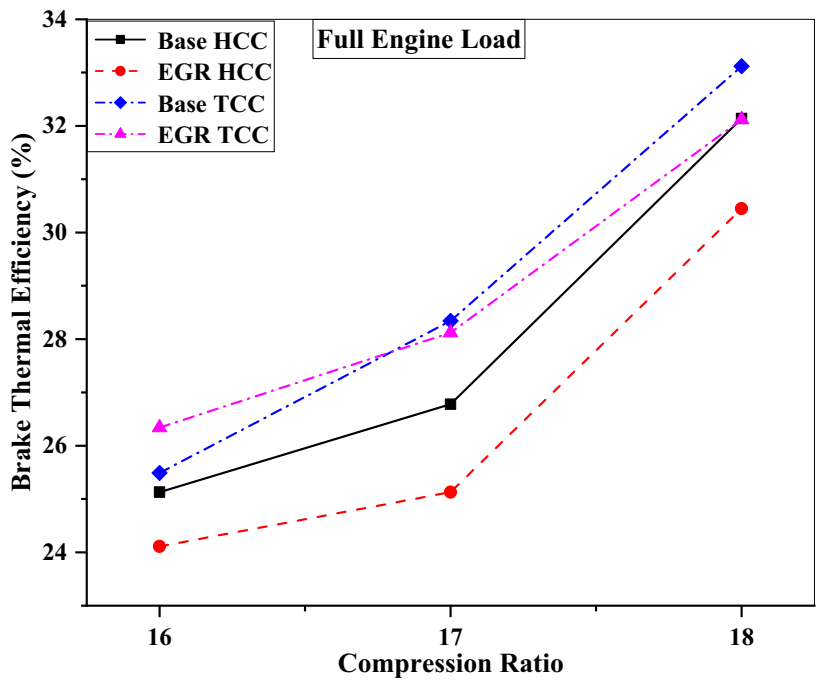

Fig. 3 Brake thermal efficiency at full engine load at various compression ratios without EGR and 10\% EGR 


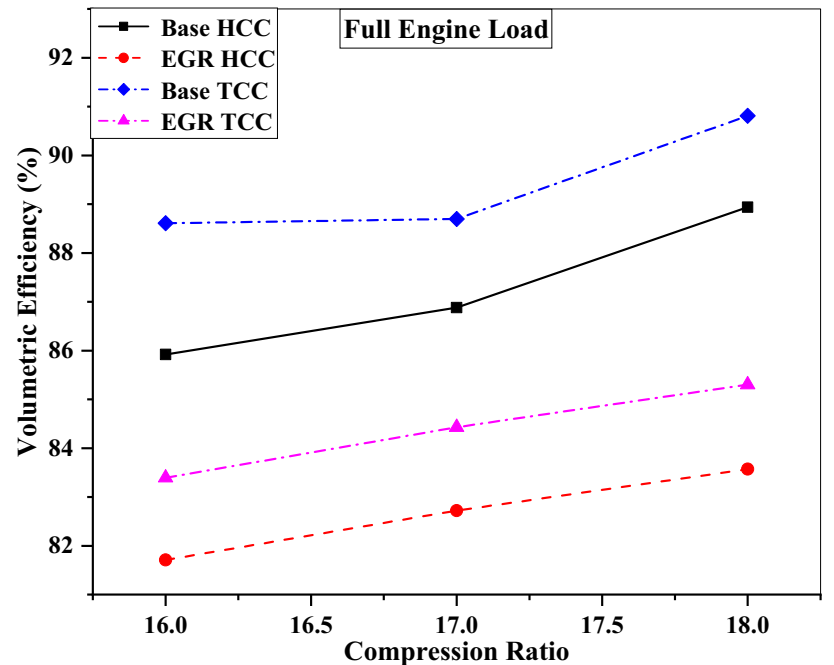

Fig. 4 Volumetric efficiency at full engine load at various compression ratios without EGR and $10 \%$ EGR

when compared between base-HCC and EGR-HCC. The maximum EGT was achieved about $292^{\circ} \mathrm{C}$ with baseTCC, and rapid combustion led to the shorter duration in burning the A-F mixture which in turn increases the overall combustion temperature. The same trend 0 decreasing EGT with the increase in CR had obtained by Hariram and Vagesh [36].

\subsection{Engine combustion characteristice}

\subsubsection{In-cylinder pressure and net he t release rate}

Cylinder pressure for full engine lo. compression ratios 16:1 to 18:1 with and wi ${ }^{2} \mathrm{GR}$ was plotted and analyzed as shown in Fig. 6. The pak in combustion pressure occurred slightly nea IDC a the compression ratio increased from 16:1 1, both the HCC and TCC geometries. At the same gine load, the peak pressure for base-TCC 60 bar) at 18:1 CR is higher than HCC (56.31 bar) $\times 7.45 \%$ shown in Fig. $6 \mathrm{~b}$.

The ur of EGR showed the negative effect on combustion chara ristic of an engine. It is because of increment in $t^{\prime} \pi$ take arge specific heat capacity and reduction in c. va 1.ty. EGR led to decrease in the in-cylinder pressure ring combustion and so combustion temperature and is cepicted in Fig. 7. At full engine load, the maximum heat release was observed with base-TCC $\left(47.06 \mathrm{~J} /{ }^{\circ} \mathrm{CA}\right)$ at 18:1 CR and also found that peak point of heat release rate was approaching near TDC with an increase in CR. The negative heat release was observed at all engine loads because of the heat transfer to the cylinder surfaces.

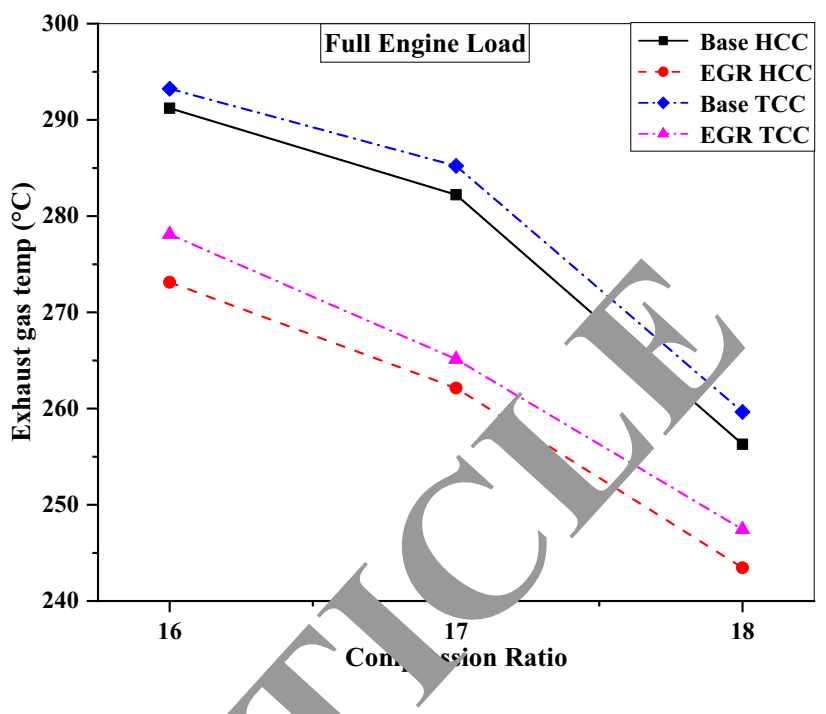

Fig. 5 Exhaust are tempera at full engine load at various compression ratio, Wit. ut EGR and $10 \%$ EGR

\subsection{2 rnition de dy}

Ignition delay of fuel is an important parameter in determining the knocking behavior of $\mathrm{Cl}$ engines. Figure 8 ows the variation of ignition delay for various compressic $n$ ratios and $10 \%$ EGR at full engine load. It has been observed that the ignition delay periods for TCC are lower than HCC at all specified engine operating conditions. Due to rapid mixing of $A-F$ mixture in TCC, fuel attains the self-ignition temperature in short span of time, and hence, delay period decreases in such a combustion chamber [13]. Ignition delay period was increased with EGR with HCC and TCC, and it is noticed from Table 4. Ignition delay period (crank angle) for all the operating conditions is converted to time (ms) by Eq. 1. At 18:1 CR, ignition delay was decreased by almost $24 \%$ with base-TCC than base-HCC:

$T(\mathrm{~ms})=\left[\frac{\text { delay period }(\mathrm{CA})}{((\mathrm{rpm} / 60) * 360)} * 1000\right]$

\subsubsection{Rate of pressure rise}

Rate of pressure rise (ROPR) indicates combustion roughness, and it is a crucial parameter in the entire engine operation. The higher the ROPR means the maximum amount of injected fuel is burnt during the pre-mixed combustion phase [37].

Figure 9 shows the comparison of ROPR at various compression ratios and 10\% EGR at full engine load. The maximum peak in ROPR was found to be $3.47 \mathrm{bar} /{ }^{\circ} \mathrm{CA} 2^{\circ} \mathrm{bTDC}$ with base-TCC, whereas for base-HCC, it was 3.36 bar $/{ }^{\circ} \mathrm{CA} 3^{\circ}$ 

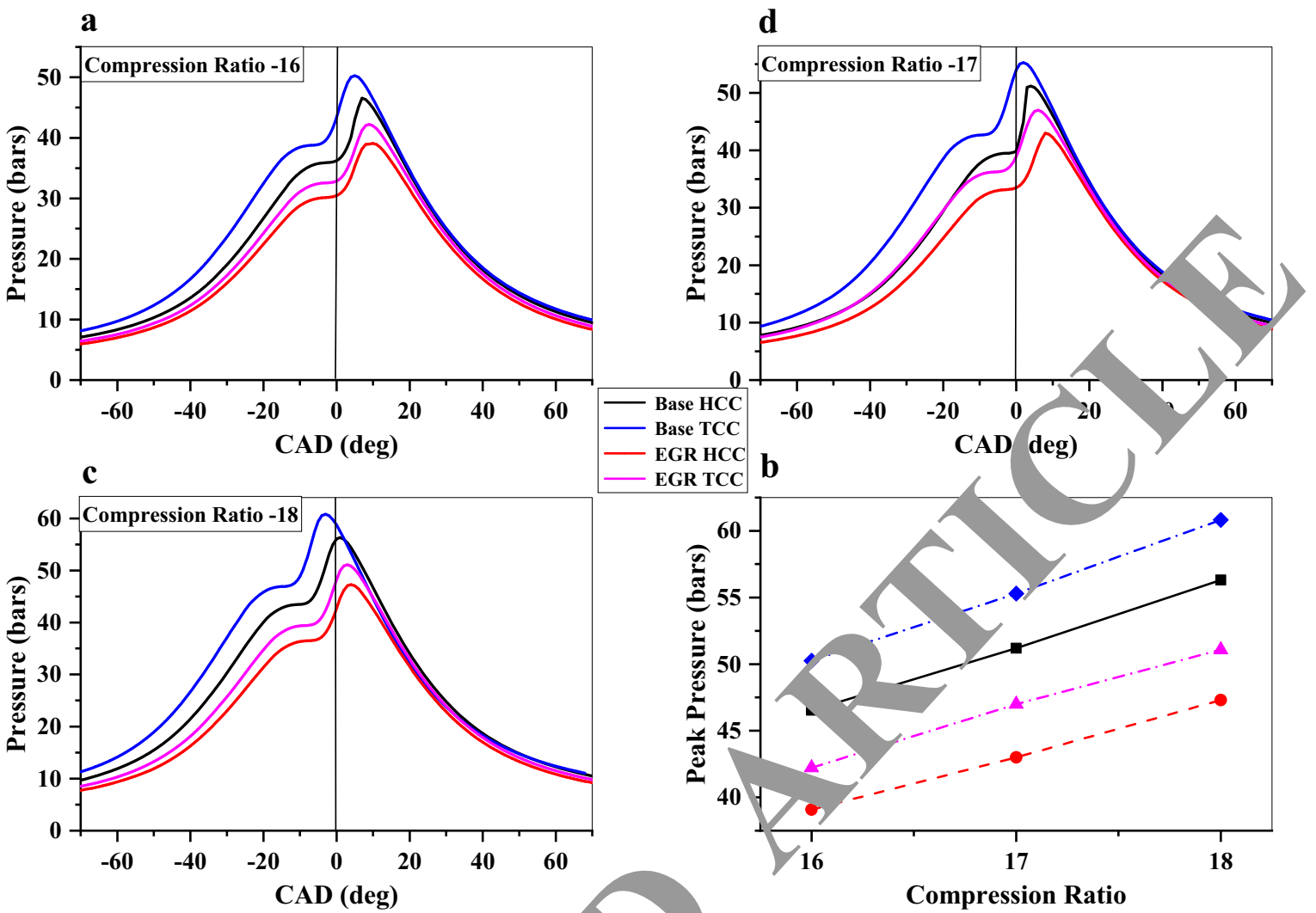

Fig. 6 In-cylinder pressure at various compression ratios an a 10\% EG,

aTDC at 18:1 CR which is lower than base-TCP, with a. $\%$ margin. It shows that combustion phenom $n c$ in both the piston geometries is almost the same. In the or side, the minimum peak in ROPR was $1.7-$ bar $/{ }^{\circ} \mathrm{CA}$ occurred at 16:1 CR with EGR-HCC. The density of -F mixing decreases as the compression ratio reduced ana ner decreased with EGR which decreases the during combustion.

\subsection{Engine emissiors re uction}

\subsection{1 $\mathrm{NO}_{x}$ emissir ns}

$\mathrm{NO}_{x}$ emissir ns are $\mathrm{p}$ 'aced at high combustion temperature, ar 4 it depends on several engine parameters like compres, rati, piston bowl geometry, equivalence rati $c$. [3,$\quad$ is noticed from Fig. 10 that $\mathrm{NO}_{x}$ emis$s$. $S y$ decreased with the use of EGR. This trend was obs ed due to decrement in $\mathrm{O}_{2}$ availability because of mixing of partial amount of the $\mathrm{O}_{2}$ of fresh intake air with recirculated gas $[30,39]$. This causes a reduction in the local flame temperature because of the spatial broadening of the flame due to the reduction in the oxygen [40]. In the end, because of endothermic chemical reaction like the dissociation of $\mathrm{H}_{2} \mathrm{O}$ and $\mathrm{CO}_{2}$, the combustion temperature was decreased [41].
At full load and 18:1 $\mathrm{CR}, \mathrm{NO}_{x}$ emissions were recorded as $745 \mathrm{ppm}$ for base-TCC, which was maximum among all specified conditions. However, for EGR-TCC it was decreased by $6.4 \%$ than base-TCC. EGR-TCC and base-HCC have produced same amount of $\mathrm{NO}_{x}$ emissions at 18:1 CR. It was noticed that $\mathrm{NO}_{x}$ emissions steadily increased with increasing $\mathrm{CR}$. The increment in $\mathrm{NO}_{x}$ emissions was due to reduction in ignition delay and increase in peak pressure, resulting in increasing combustion temperature.

\subsubsection{Carbon monoxide emissions}

Carbon monoxide (CO) emissions are produced due to incomplete combustion, and it mainly depends on $\mathrm{A}-\mathrm{F}$ ratio [42]. The use of EGR decreases in-cylinder $\mathrm{O}_{2}$ availability during combustion and also slows down the reaction rates of the $\mathrm{A}-\mathrm{F}$ mixture, hence producing lower temperatures [30]. At such a temperature, the flame front propagation could not be sustained with lean mixtures. Thus, the A-F mixture does not combust completely, causing $\mathrm{CO}$ emissions as depicted in Fig. 11. It was observed that CO emissions are decreasing with an increase in compression ratio due to better combustion. Being in agreement with references $[43,44]$, peak in $\mathrm{CO}$ emissions was observed as EGR proportion increased in fresh A-F mixture. Minimum 

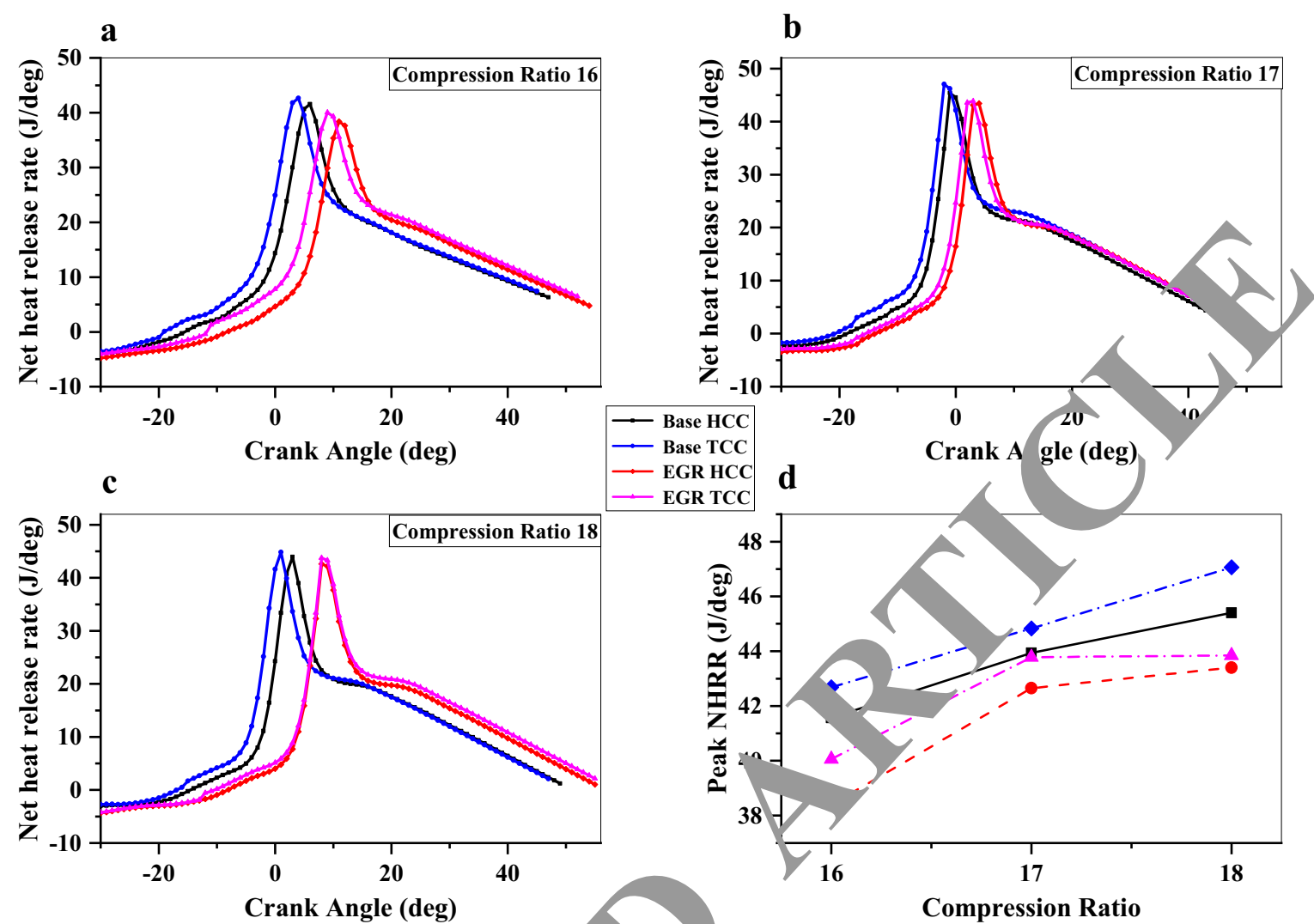

Fig. 7 Net heat release rate at various compression ratios a $10 \%$ EG

rull engine load

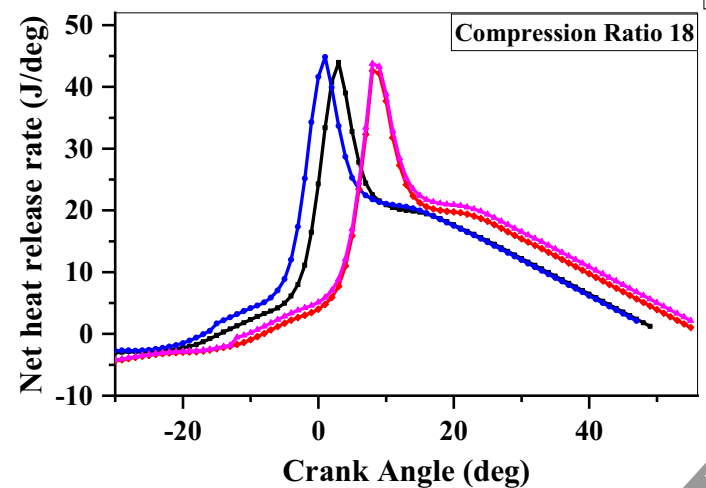

Compression Ratio

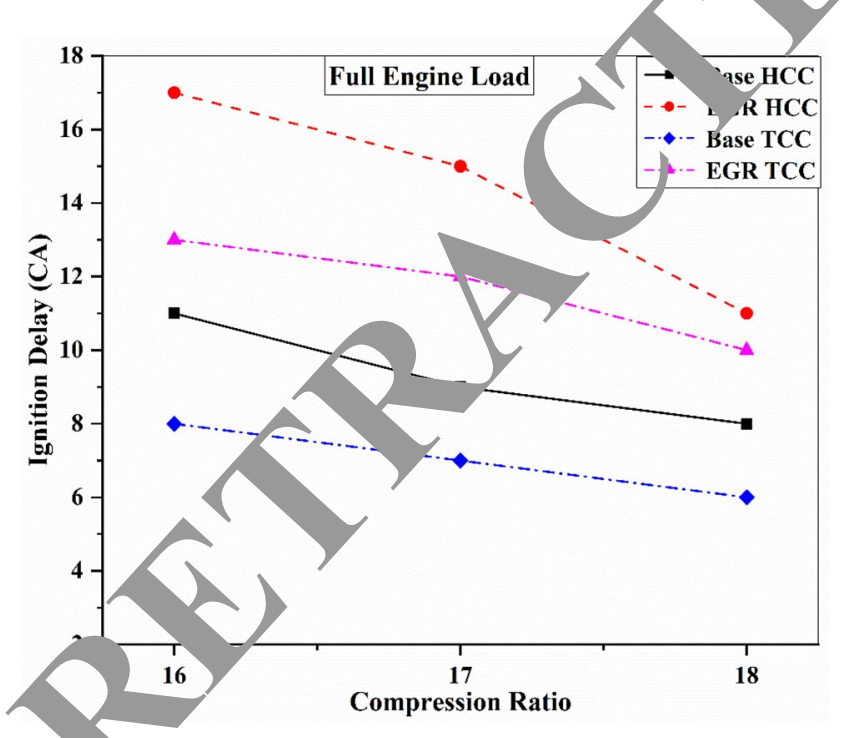

Fig. 8 Ignition delay at various compression ratios and 10\% EGR at full engine load

CO emissions (0.05\%) were achieved at base-TCC with 18:1 CR. TCC piston geometries had shown lower CO emissions than HCC due to enhanced combustion $[13,17]$. An interesting fact came to observation was that the $\mathrm{CO}$ emissions for EGR-TCC and base-HCC were almost same at all the compression ratios.

\subsubsection{Hydrocarbon emissions}

Figure 12 shows the $\mathrm{HC}$ emissions at varying compression ratios and $10 \%$ EGR at full engine load. It is observed that the $\mathrm{HC}$ emissions steadily decrease with increasing compression ratio. This is because the increase in the intake air temperature at the end of compression stroke improves the combustion temperature and reduces the charge dilution that leads to better combustion and reduction in $\mathrm{HC}$ emissions. It was seen that with the induction of exhaust gases with fresh charge, $\mathrm{HC}$ emissions were increased. Fuel quantity being injected for any specific condition with or without EGR is remained same. Recirculated exhaust gas decreases the $\mathrm{O}_{2}$ availability for combustion which leads to increase in $\mathrm{HC}$ emissions from an engine than the base condition [43]. The maximum value of $\mathrm{HC}$ emissions is observed to be $48 \mathrm{ppm}$ at 16:1 CR with EGR-HCC. TCC has shown lower $\mathrm{HC}$ emissions at all the specified conditions than $\mathrm{HCC}$; it is due to better mixing of A-F because of improved air swirl [14]. At 18:1 CR, base-TCC has shown 

performed on DI engine at full engine load
Table 4 Experiments

\begin{tabular}{|c|c|c|c|}
\hline Piston & Compression ratios & EGR & Output parameters \\
\hline HCC piston & $16: 1,17: 1,18: 1$ & $\begin{array}{l}\text { Without EGR } \\
10 \% \text { EGR }\end{array}$ & $\begin{array}{l}\text { Engine performance } \\
\text { Brake specific fuel consumption } \\
\text { Brake thermal efficiency } \\
\text { Exhaust gas temperature } \\
\text { Volumetric efficiency }\end{array}$ \\
\hline TCC piston & $16: 1,17: 1,18: 1$ & $\begin{array}{l}\text { Without EGR } \\
10 \% \text { EGR }\end{array}$ & $\begin{array}{l}\text { Engine combustion } \\
\text { Net heat rele ral? } \\
\text { Pressure rise du com ustion } \\
\text { Engine emissions } \\
\text { Carbo monoxide } \\
\text { Hydroca } \\
\text { Sxides of }\end{array}$ \\
\hline
\end{tabular}
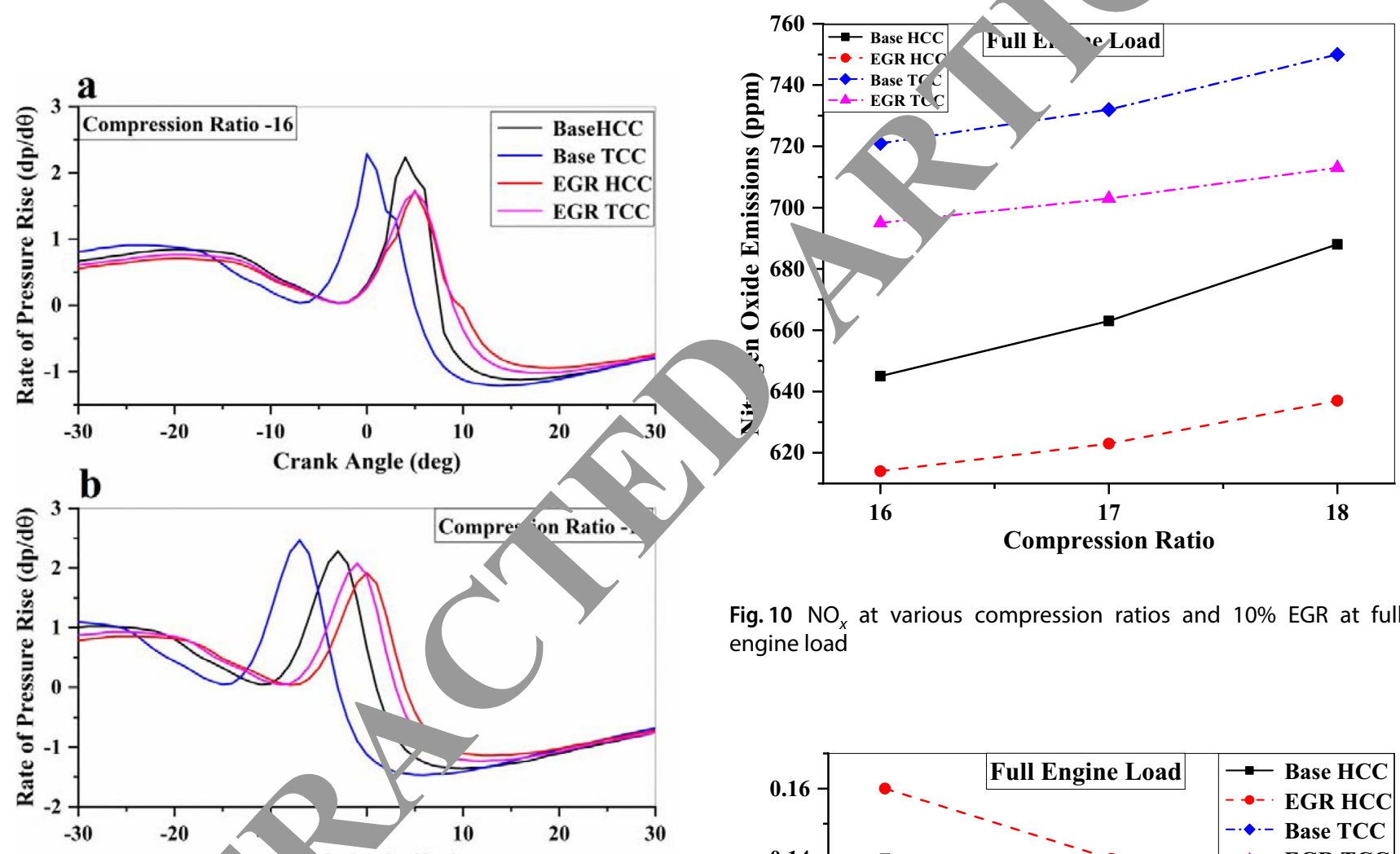

Fig. $10 \mathrm{NO}_{x}$ at various compression ratios and 10\% EGR at full engine load

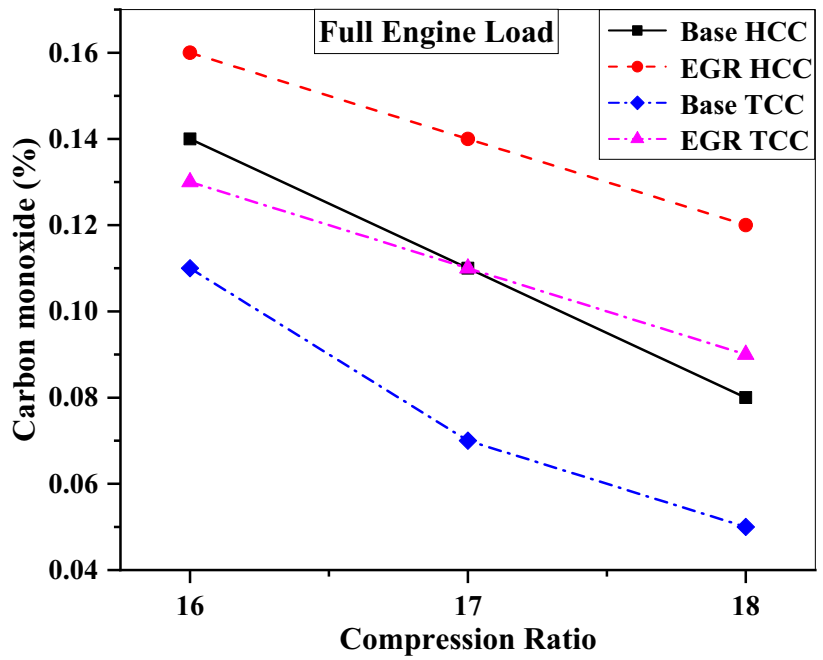

Fig. 11 CO emissions at various compression ratios and 10\% EGR at full engine load 


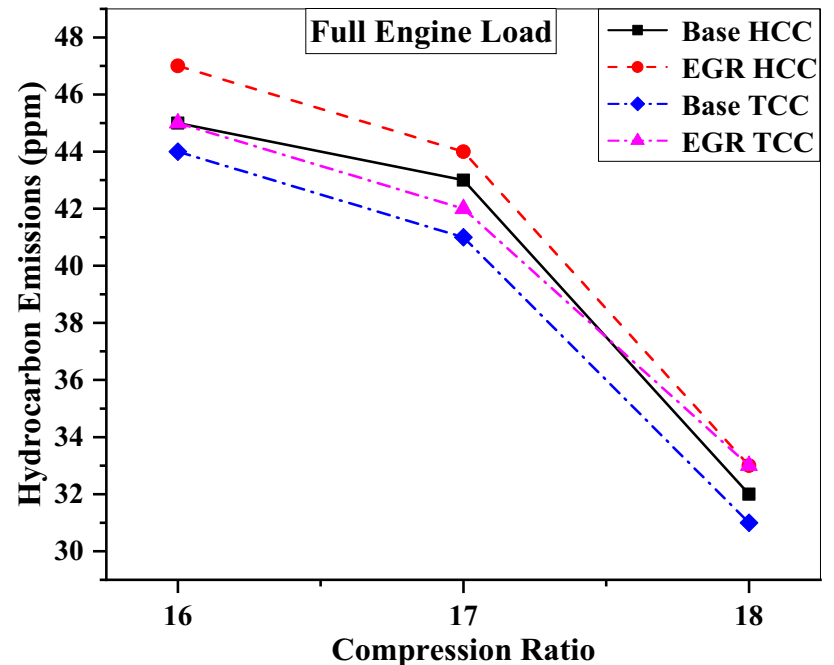

Fig. $12 \mathrm{HC}$ emissions at various compression ratios and 10\% EGR at full engine load

$8.82 \%$ of decrement in HC emissions than base-HCC. Summary of the results is shown in Table 5, which represents the effect of piston geometries, CR and EGR on the engine behavior Table 6.

\section{Conclusions}

In this research, the effect of toroidal combustion chamber (TCC) geometry on performance, combustion and emissions of a compression ignition $(\mathrm{Cl})$ engine with variable compression ratio (CR) and exhaust gas recirculation (EGR) was investigated. The conclusions derived rrom the present study are encapsulated as below:

- Improved air swirling by the $\mathrm{T}^{\prime}$ pistor er riches the air-fuel mixing and hence enhan the jrake thermal efficiency (BTE) than hemi sperical c nbustion chamber (HCC). Maximum BTE chieved with base-TCC was $33.12 \%$, which was hi her $-67 \%$ than base-HCC.

- Transcend combu-tion a result of enhanced mixture formation in $\mathrm{TC}$ 'owers $\mathrm{C}$, and $\mathrm{HC}$ emissions as compared to $\mathrm{HCC}$, isto. eometry. However, $\mathrm{NO}_{x}$ emissions increased $n$ the in, rease in compression ratio and decrea. I w the induction of EGR. $\mathrm{NO}_{x}$ emissions increasea th base-TCC by $10.54 \%$ than base-HCC, wh nas it de,reased by $3.19 \%$ with EGR-TCC at 18:1 CR. The incr. ent in $\mathrm{NO}_{x}$ emissions was observed due to an in reased maximum rate of pressure rise caused by
Table 5 Ignition delay period at various compression ratios and $10 \%$ EGR in terms of crank angle and time higher air swirl by TCC piston bowl as compared to HCC.

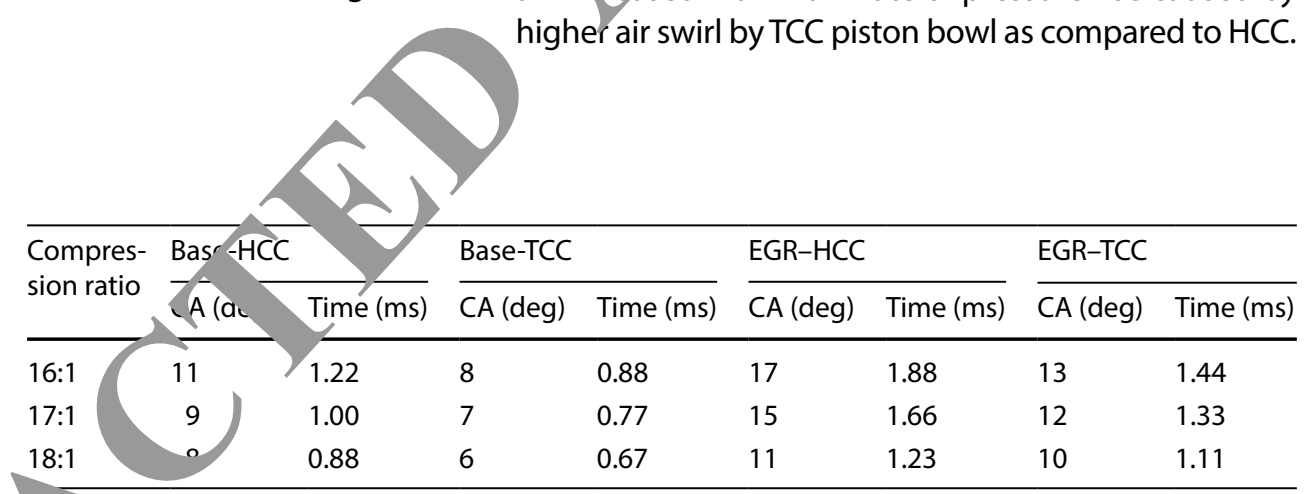

Table 6 Summary of res,

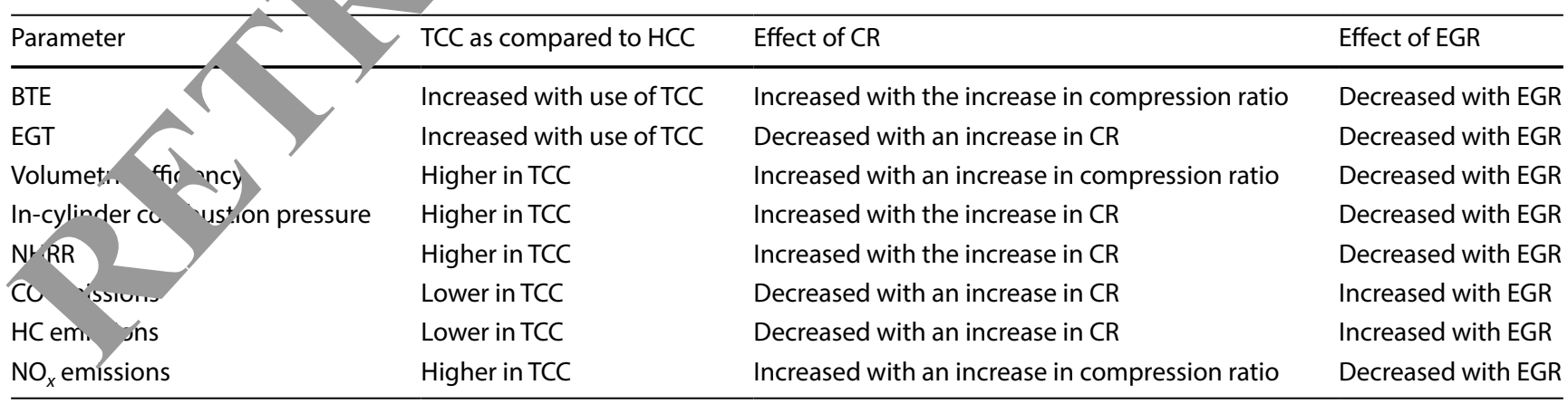


The present study reveals that the performance, emissions and combustion characteristics of variable compression ratio test rig implemented with EGR can be improved by using suitable combustion chamber geometry and compression ratio.

\section{Compliance with ethical standards}

Conflict of interest The author declares that they have no competing interests.

\section{Appendix}

$$
\begin{aligned}
& \frac{\Delta N}{N}=\frac{1}{1500}=0.0667 \% \\
& \frac{\Delta m}{m}=\frac{0.1}{12}=0.8333 \% \\
& \mathrm{BP}=\frac{2 \pi \mathrm{NT}}{60.1000}=\frac{2 \pi \mathrm{Nmgl}}{60000}=\frac{2 \times 3.14 \times 1500 \times 12 \times 9.81 \times 0.185}{60000}=3.421 \mathrm{~kW} \\
& \frac{\partial \mathrm{BP}}{\partial N}=\frac{2 \pi \mathrm{mgl}}{60000}=\frac{2 \times 3.14 \times 12 \times 9.81 \times 0.185}{60000}=0.00228061 \\
& \frac{\partial \mathrm{BP}}{\partial m}=\frac{2 \pi \mathrm{Ngl}}{60000}=\frac{2 \times 3.14 \times 1500 \times 9.81 \times 0.185}{60000}=0.28507597 \\
& \Delta \mathrm{BP}=\sqrt{\left(\Delta N \frac{\partial \mathrm{BP}}{\partial N}\right)^{2}+\left(\Delta m \frac{\partial \mathrm{BP}}{\partial m}\right)^{2}} \\
& \Delta \mathrm{BP}=\sqrt{(1 \times 0.00228061)^{2}+(0.1 \times 0.28507597)^{2}} \\
& \triangle \mathrm{BP}=0.028598676 \mathrm{~kW} \\
& \frac{\Delta \mathrm{BP}}{\mathrm{BP}}=\frac{0.028598676}{3.421}=0.836 \% \\
& \mathrm{MFC}=\frac{f \times 3600 \times \rho}{t \times 1000}=\frac{7.125 \times 3600 \times 0.8}{30 \times 1000}=0.698535 \frac{\mathrm{kg}}{\mathrm{h}} \\
& \frac{\partial \mathrm{MFC}}{\partial t}=\frac{f \times 3600 \times \rho}{(t)^{2} \times 1000}=\frac{7.125 \times 3}{30 \times 30 \times 1000}=-0.0232845 \\
& \frac{\partial \mathrm{MFC}}{\partial f}=\frac{3600 x \rho}{t \times 1000}=35,00 \lambda \cdot 817=0.09804
\end{aligned}
$$

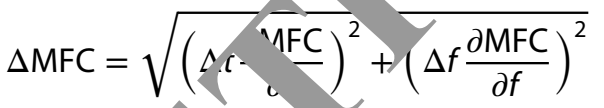

$$
\begin{aligned}
& \Delta \mathrm{MFC}=\sqrt{(0.2 x-0.0232845)^{2}+(0.1 \times 0.09804)^{2}} \\
& \begin{aligned}
\Delta M & =0.0 \quad 253807 \frac{\mathrm{kg}}{\mathrm{kWh}} \\
M F & =\frac{010853807}{0.698535}=1.554 \%
\end{aligned}
\end{aligned}
$$

$\mathrm{BSFC}=\frac{\mathrm{MFC}}{\mathrm{BP}}=\frac{0.698535}{3.421}=0.204190295 \frac{\mathrm{kg}}{\mathrm{kWh}}$

$\frac{\partial \mathrm{BSFC}}{\partial \mathrm{BP}}=\frac{\mathrm{MFC}}{(\mathrm{BP})^{2}}=\frac{0.698535}{(3.421)^{2}}=-0.059687312$

$\frac{\partial B S F C}{\partial M F C}=\frac{1}{B P}=\frac{1}{3.421}=0.292312219$

$\triangle \mathrm{BSFC}=\sqrt{\left(\triangle \mathrm{BP} \frac{\partial \mathrm{BSFC}}{\partial \mathrm{BP}}\right)^{2}+\left(\Delta \mathrm{MFC} \frac{\partial \mathrm{BSFC}}{\partial \mathrm{MFC}}\right)^{2}}$

$\Delta \mathrm{BSFC}=\sqrt{(0.028598676 x-0.059687312)^{2}+(0.0108538 \mathrm{C} \times 0.292312219)^{2}}$

$\triangle B S F C=0.003602749243 \frac{\mathrm{kg}}{\mathrm{kWh}}$

$\frac{\Delta \mathrm{BSFC}}{\mathrm{BSFC}}=\frac{0.003602749243}{0.204190295}=1.764 \%$

$=\sqrt{\left(\frac{\Delta \mathrm{CO}}{\mathrm{CO}}\right)^{2}+\left(\frac{\Delta \mathrm{BP}}{\mathrm{BP}}\right)^{2}}$

$=\sqrt{(0.00597)^{2}+(r 00836)}$

$=1.027 \%$

$$
\begin{aligned}
& =\sqrt{\left(\frac{\Delta \mathrm{CO}_{2}}{(2}\right)+\left(\frac{\Delta \mathrm{BP}}{\mathrm{BP}}\right)^{2}} \\
& =\sqrt{\left(0.0(35587)^{2}+(0.00836)^{2}\right.}
\end{aligned}
$$

$7.909 \%$

\section{References}

1. Outlook AE (2002) with projections to 2040. US Energy Information Administration. 2001, DOE/EIA-0383, December

2. Agarwal AK et al (2013) Characterization of exhaust particulates from diesel fueled homogenous charge compression ignition combustion engine. J Aerosol Sci 58:71-85. https://doi. org/10.1016/j.jaerosci.2012.12.005

3. Singh G, Singh AP, Agarwal AK (2014) Experimental investigations of combustion, performance and emission characterization of biodiesel fuelled $\mathrm{HCCl}$ engine using external mixture formation technique. Sustain Energy Technol Assess 6:116-128. https://doi.org/10.1016/j.seta.2014.01.002

4. Maurya RK, Agarwal AK (2014) Experimental investigations of performance, combustion and emission characteristics of ethanol and methanol fueled $\mathrm{HCCl}$ engine. Fuel Process Technol 126:30-48. https://doi.org/10.1016/j.fuproc.2014.03.031

5. Najt PM, Foster DE (1983) Compression-ignited homogeneous charge combustion, SAE Technical Paper

6. Prasad B et al (2011) High swirl-inducing piston bowls in small diesel engines for emission reduction. Appl Energy 88(7):2355-2367

7. Ogawa $\mathrm{H}$, et al. (1996) Three-dimensional computation of the effects of the swirl ratio in direct-injection diesel engines on $\mathrm{NO}_{x}$ and soot emissions, SAE Technical Paper 
8. Arcoumanis C, Bicen A, Whitelaw J (1983) Squish and swirlsquish interaction in motored model engines. J Fluids Eng 105(1):105-112

9. De Risi A, Donateo T, Laforgia D (2003) Optimization of the combustion chamber of direct injection diesel engines, SAE Technical Paper

10. Saito T, et al. (1986) Effects of combustion chamber geometry on diesel combustion, SAE Technical Paper

11. Subramanian $S$ et al. (2016) Piston bowl optimization for single cylinder diesel engine using CFD, SAE Technical Paper

12. Brijesh $P, A b h i s h e k S$, Sreedhara $S$ (2015) Numerical investigation of effect of bowl profiles on performance and emission characteristics of a diesel engine, SAE Technical Paper

13. Jaichandar $S$, Annamalai K (2012) Influences of re-entrant combustion chamber geometry on the performance of Pongamia biodiesel in a DI diesel engine. Energy 44(1):633-640

14. Jyothi U, Reddy KV (2017) Experimental study on performance, combustion and emissions of diesel engine with re-entrant combustion chamber of aluminum alloy. Mater Today: Proc 4(2):1332-1339

15. Viswanathan K, Pasupathy B (2017) Studies on piston bowl geometries using single blend ratio of various non-edible oils. Environ Sci Pollut Res Int 24(20):17068-17080. https:// doi.org/10.1007/s11356-017-9344-3

16. Khan S, Panua R, Bose PK (2018) Combined effects of piston bowl geometry and spray pattern on mixing, combustion and emissions of a diesel engine: a numerical approach. Fuel 225:203-217. https://doi.org/10.1016/j.fuel.2018.03.139

17. Karthickeyan V (2019) Effect of combustion chamber bowl geometry modification on engine performance, combustion and emission characteristics of biodiesel fuelled diesel engi e with its energy and exergy analysis. Energy 176:830-852. hit ://doi.org/10.1016/j.energy.2019.04.012

18. Vedharaj S et al (2015) Optimization of combust on bowl geometry for the operation of kapok biodiesel-dies in a stationary diesel engine. Fuel 139:561-56

19. Gnanamoorthi V, Marudhan NM, Gobalak: nin D $(20,6)$ Effect of combustion chamber geometry on prmance, combustion, and emission of direct ir.jection dies engine with ethanol-diesel blend. Therm Sc 20:937-946

20. Karthickeyan V, Balamurugan $P$, Ram ingam $S$ 2016) Studies on orange oil methyl ester in diesel en wit' hemispherical and toroidal combustion chai hor. Thermal Sci 20:981-989

21. Kumar V (2017) Experimental Ir. ction of piston bowl geometry effects on performance and emissions characteristics of diesel en ginu $t$ varich/e injection pressure and timings. Int J Am! t F 39(7):685-693. https://doi. org/10.1080/01/2075 017.1333041

22. Ganji PR, Sinc RN, Raju C, Srinivasa Rao S (2018) Design of piston bow ge try for better combustion in direct-injection com rression . ition engine. Sādhanā 43(6):92

23. Dhine, h B, Annamalai M, Lalvani IJ, Annamalai K (2017) Studies 0 . he flut nce of combustion bowl modification for the operat of $C$ ymbopogon flexuosus biofuel based diesel D. ds in a 1 diesel engine. Appl Therm Eng 112:627-637

Kat I CD Vysyaraju RKR, Surapaneni SR, Ganji PR (2019) Effect n-butanol/diesel blends and piston bowl geometry on combu. In and emission characteristics of $\mathrm{Cl}$ engine. Environ $\mathrm{Sci}$ Pohut Res 26(2):1661-1674

25. Balasubramanian D, Arumugam SRS, Subramani L, Chellakumar IJLJS, Mani A (2018) A numerical study on the effect of various combustion bowl parameters on the performance, combustion, and emission behavior on a single cylinder diesel engine. Environ Sci Pollut Res 25(3):2273-2284
26. Zhang T, Eismark J, Munch K, Denbratt I (2020) Effects of a wave-shaped piston bowl geometry on the performance of heavy duty diesel engines fueled with alcohols and biodiesel blends. Renew Energy 148:512-522

27. Sener R, Yangaz MU, Gul MZ (2020) Effects of injection strategy and combustion chamber modification on a single-cylinder diesel engine. Fuel 266:117122

28. Arumugam S, Pitchandi K, Arventh M, Mahesh'umar P (2015) Effect of re-entrant and toroidal combustion chambers in a $\mathrm{DICl}$ engine. In: Applied mechanics and te $2 \mathrm{Is}$, 'ol 787. Trans Tech Publications Ltd, pp 722-726

29. Ladommatos N, Abdelhalim S, Zhaø H (2000) I - effects of exhaust gas recirculation on diesel bustion and emissions. Int J Engine Res 1(1):107-126

30. Agarwal D, Singh SK, Agarw , AK (2011) L ect of Exhaust Gas Recirculation (EGR) on perf mance, elnissions, deposits and durability of a constan+(spe compression ignition engine. Appl Energy 88(8):290 907

31. Ozawa G (1997) V irable npression ratio engine. Google Patents

32. Jaichandar S, nna 'ai K (2013) Combined impact of injection pressı... and co. ustion chamber geometry on the performanct f a biodiesel fueled diesel engine. Energy 55:330-?. doi.org/10.1016/j.energy.2013.04.019

33. Raj ARGS, 'likarjuna JM, Ganesan V (2013) Energy efficient pi tan configu ation for effective air motion-a CFD study. Appl En ry, $247-354$

34. Chal $\epsilon$ A B, barnescu R (1999) Diesel engine reference book. Society oi aytomotive engineers. Bath Press, Bath

25. Ganesan V (2012) Internal combustion engines. McGraw Hill Education (India) Pvt Ltd, Bengaluru

36 Hariram V, Vagesh Shangar R (2015) Influence of compression ratio on combustion and performance characteristics of direct injection compression ignition engine. Alex Eng J 54(4):807814. https://doi.org/10.1016/j.aej.2015.06.007

37. Selim M, Radwan MS, Elfeky SM (2003) Combustion of jojoba methyl ester in an indirect injection diesel engine. Renew Energy 28(9):1401-1420

38. Heywood JB (1988) Internal combustion engine fundamentals, vol 930. Mcgraw-hill, New York

39. Guo M et al (2015) A short review of treatment methods of marine diesel engine exhaust gases. Proc Eng 121:938-943

40. Hussain J et al (2012) Retracted: effect of exhaust gas recirculation (EGR) on performance and emission characteristics of a three cylinder direct injection compression ignition engine. Elsevier, Amsterdam

41. Maiboom A, Tauzia X, Hétet J-F (2008) Experimental study of various effects of exhaust gas recirculation (EGR) on combustion and emissions of an automotive direct injection diesel engine. Energy 33(1):22-34

42. Park SH, Youn IM, Lee CS (2010) Influence of two-stage injection and exhaust gas recirculation on the emissions reduction in an ethanol-blended diesel-fueled four-cylinder diesel engine. Fuel Process Technol 91(11):1753-1760

43. De Serio D, de Oliveira A, Sodré JR (2017) Effects of EGR rate on performance and emissions of a diesel power generator fueled by B7. J Braz Soc Mech Sci Eng 39(6):1919-1927

44. Kumar BR et al (2016) Effect of a sustainable biofuel-n-octanolon the combustion, performance and emissions of a DI diesel engine under naturally aspirated and exhaust gas recirculation (EGR) modes. Energy Convers Manag 118:275-286

Publisher's Note Springer Nature remains neutral with regard to jurisdictional claims in published maps and institutional affiliations. 